\title{
ÉTICA E ONTOLOGIA EM KANT ETUGENDHAT
}

\author{
Daniel Christino
}

Faculdades Alves Faria

dchristino@02.net.br

\begin{abstract}
RESUMO: A noção de ética defen dida pela tradição analítica está baseada no pressuposto de que toda ética deve ser normativa e deve, portanto, justificar a adoção de qualquer princípio moral a partir de uma argumentação racional. No livro Liç̧ões sobre ética, Ernst Tugendhat procura dialogar com a tradição filosófica - Kant em especial - a fim de identificar os principais sistemas éticos e seus pontos positivos enegativos. A argumentação de Tugendhat ten de para o contratualismo contemporâneo, embora ainda procure manter alguns aspectos kantianos ligados à fundamentação dos imperativos categóricos. Este artigo argumenta que a interpretação de Tugendhat sobre o sistema ético kantiano é correta apenas no quetange à formulação dos imperativos. A o ignorar a noção de liberdade, Tugendhat abre espaço para o ceticismo ético porque não podeaprofundar a discussão em âmbito ontológico, como o próprio Kant o fez.
\end{abstract}

Palavras-chave: Kant, ontologia, juízos morais, justificação moral, Tugendhat.

\section{Introdução}

A noção de razão está na base do pensamento moral kantiano da mesma forma que uma coluna de concreto serve de alicerce para um edifício. Sem ela, toda elaborada construção kantiana soçobra como um frágil castelo de cartas. Q ual é essa noção? Na esteira dessa pergunta, Tugendhat pretende fazer ruir o sistema kantiano, mas não sem antes retirar de lá o que lhe interessa, isto é, um conceito de razão mais fraco do que o kantiano, mas ainda assim fundante.

A crítica de Tugendhat à moral kantiana se processa em duas etapas. Primeiro, ele procura realizar uma leitura da Fundamentação da metafísica dos costumes que difere dois tipos de razão; um referente aos imperativos categóricos e o outro aos imperativos hipotéticos. 
Tanto um como o outro pressupõem a razão, mas fazem uso dela de maneira qualitativamente distinta. Enquanto os imperativos categóricos erguem-se sobre o terreno mais sólido de uma razão absoluta (tomada como "fundante"), os juízos hipotéticosfazem uso deuma razão mais prosaica, enten dida como capacidade de concluir, ou seja, derivar de certas premissas sua conclusão necessária. Em um segundo momento, Tugendhat passa à carga contra a razão fundante de Kant, resumindo seu argumento à prova de que esse conceito é um non sequitur.

$\mathrm{N}$ a verdade, Tugendhat quer inverter a priorização de Kant. Enquanto o filósofo de Königsberg dá extrema importância à Razão (aqui cabe a maiúscula), enquanto faculdade do espírito capaz de se tornar fundamento de um agir moral, e assume a capacidade de concluir como um caso específico dela, Tugendhat afirma queKant não pode demonstrar com clareza o que seria essa R azão e que isso não passa, na verdade, de uma derivação daquela característica de concluir tão comum no nosso dia-a-dia. Invertendo o quadro, Tugendhat acredita ter pego Kant pelo pé, pois não seria possível derivar uma Razão fundadora a partir da característica, efetivamente prosaica, de podermos concluir alguma coisa a partir de outras. Esse seria o non sequitur em questão.

$M$ as Kant afirma explicitamente, na terceira seção da Fundamentação, que não é possível à razão provar a moralidade do homem entendida como liberdade. 0 conceito de liberdade deve ser pressuposto e a única razão plausível para tanto é a de que somos seres fenomenais e numenais ao mesmo tempo, ou seja, habitamos dois mundos diferentes e devemos obediência a dois princípios distintos: às leis naturais e à liberdade. $M$ as, ao mesmo tempo, não é possível ao homem fundamentar suficientemente a liberdade e, portanto, a moralidade, senão apelando para um mundo inteligível, um mundo intelectual, do qual apenas a razão faz parte. Esse recurso, que para K ant serve como um salva-vidas no mar das contradições, é para Tugendhat um salto mortal, uma pirueta kantiana, um 
malabarismo teórico que divide o mundo em dois planos, o sensível e o espiritual.

0 que, entretanto, interessa a Tugendhat é salvar os conteúdos do imperativo categórico como princípios fundamentais de ação. 0 universalismo e a idéia de não-instrumental ização dos homens Ihe servem de argumento contra o contratualismo, mas esses princípios só resistem se propriamente justificados, o que Tugendhat faz apelando para o outro conceito mais prosaico de razão de Kant; 0 da faculdade de concluir. A ssim, se queres viver em nossa sociedade, tens que agir de acordo com os dois princípios fundamentais da universalidade e da não-instrumentalização, ou seja, se queres $x$, tens de fazer y. U m juízo perfeitamente hipotético e, segundo 0 próprio Tugendhat, a única forma pela qual a razão funciona.

M as será que a crítica de Tugendhat se sustenta diante da Fundamentação como um todo, ou seja, levando-se em consideração a terceira seção e os limites que Kant impõe à própria idéia de uma fundamentação da liberdade? Essa pergunta tentaremos responder com uma primeira análise dos argumentos de Tugendhat e da terceira seção da Fundamentação de Kant. D epois, exporemos um pouco o próprio pescoço ao argumentar pela precedência de uma ontologia à toda ética, o que, via de regra, é feito a partir da pergunta antropológica.

\section{Tugendhat}

Comecemos analisando a passagem onde Tugendhat elabora sua crítica à fundamentação kantiana da moral. D evemos, contudo, ressaltar que a crítica de Tugendhat está diretamente relacionada com a identificação de dois tipos de razão dentro do próprio pensamento kantiano. Isso pode ser colocado em dúvida.

Tugendhat inicia sua crítica ao perguntar como podemos entender Kant quando ele diz que seres racionais podem agir de acordo com a representação de leis. A primeira hipótese que ele 
levanta é a de que Kant está se referindo a leis do conhecimento teórico, que podem ser assumidas no campo da moral através de sua representação. "Isto soa como se fossem as mesmas leis, e na mesma formulação, constatadas na natureza pelo entendimento teórico e 'por cuja representação' então se pode agir." ${ }^{1}$ Esse não parece ser o caso, afirma Tugendhat, já que o imperativo categórico não corresponde a nenhuma lei da natureza e, ao mesmo tempo, é um claro princípio prático.

Entretanto, o mesmo não parece acontecer com os imperativos hipotéticos. "Aos assim chamados imperativos hipotéticos corresponde uma lei natural, mas nunca na mesma formulação" (p. 142). 0 fato de que não seja a mesma formulação faz muita diferença. $0 \mathrm{~s}$ imperativos hipotéticos se assemelham às fórmulas mais simples das leis naturais: "Sempre que $x$, então y". Contudo, há uma reformulação ao se passar para o campo da moralidade e assim, para os imperativos hipotéticos. "Da proposição teórica 'Sempre que $x$, então $y$ ' resulta portanto a proposição prática 'Sempre que queres $y$, faz $x^{\prime \prime \prime}$ (p. 142). Dessa forma, conclui Tugendhat: "As leis, de acordo com 'cujas representações' podese agir, não são pois leis naturais nem sequer no caso dos imperativos hipotéticos, apesar de se fundamentarem em tais" (p. 142). Assim, fica excluída a possibilidade de as proposições práticas serem derivadas de proposições teóricas sobre a natureza. Depois, ele apresenta a designação estabelecida por Kant desses "princípios práticos como mandamentos da razão e suas fórmulas - portanto a expressão linguística - como imperativos" (p. 142). Esses imperativos, segundo Tugendhat, Kant entende como exclusivamente aqueles que se fundam na razão.

Tugendhat, então, volta-se para o parágrafo 13 da Fundamentação e introduz uma nova pergunta retórica, que pretende apontar o caminho da investigação: M as o que se quer dizer quando se diz que estas regras são mandamentos da razão? Para Tugendhat, a resposta de Kant é a de que estes mandamentos "dizem que seria bom fazer ou deixar de fazer" (§ 14). Tugendhat concorda com Kant 
afirmando que podemos até mesmo reformular a fórmula e injetar nela a idéia de bom. "Se queres y, é bom fazer x". D e certa forma, a fórmula dos imperativos hipotéticos é exatamente àquela que Tugendhat afirma ser a única possível a juízos morais. Assim, seu próximo passo argumentativo éfundamental para sua crítica à Kant, porque permite abandonar os imperativos categóricos e manter os hipotéticos. Pois assim ele afirma uma certa concepção de razão ao mesmo tempo em que descarta outra.

Tugendhat cita, agora, duas formulações de Kant para 0 conceito de razão, assumindo que elas são distintase cada uma aponta em uma direção. A primeira citação encontra-se no mesmo § 14 da Fundamentação e diz o seguinte:

praticamente bom, contudo, é o que determina a vontade por intermédio das representações da razão, portanto não por causas subjetivas, mas objetivamente, i. é, por razões válidas para todo ser racional como tal. (p. 143)

A essa caracterização da razão, Tugendhat opõe uma outra, um pouco mais discreta, apresentada por Kant no § 12. "para a derivação das ações a partir de leis é exigido razão" (p. 143).

$\mathrm{Na}$ seqüência, Tugendhat introduz uma outra questão, no sentido de esclarecer a própria argumentação em torno dessas duas acepções distintas de razão. "O que se deve entender em geral por 'razão' e 'razão prática'?' (p. 143). A primeira resposta de Kant é a deque razão pode ser enten dida no sentido de faculdade de concluir como explicitado na segunda caracterização el encada por Tugendhat. Entretanto existe uma outra acepção, de acordo com a qual ela seria a faculdade da fundamentação (rationem reddere). Este conceito, afirma Tugendhat, é mais geral porque, a princípio, inclui a própria faculdade de concluir, já que ela se torna apenas um caso específico de fundamentação (por conclusões) e, portanto, tem menos importância para o projeto kantiano. É desse conceito mais geral que parte Kant ao explicar o termo bom. 
A qui, nessa diferenciação, o problema ganha uma formulação mais aguda.

Agora, muito fala a favor de se entender o discurso sobre regras razoáveis ou racionais nesse sentido. Pois numa tal regra, tudo depen de de ela fundamentar objetivamente um determinado agir, como Kant diz aqui, e não, de ela ser apenas uma regra geral, da qual podem ser derivadas ações individuais. (p. 144)

Assim, para o projeto kantiano, uma Razão, capaz de fundamentar em si mesma regras morais, é mais importante do que aquela que pretende apenas ser uma faculdade de concluir. Entretanto, e aqui começa a crítica de Tugendhat, Kant entende o próprio imperativo categórico a partir desse sentido mais prosaico. "C ontudo, veremos que, a propósito da questão de como enten der o imperativo categórico, o próprio Kant se orientou pel o outro sentido [da razão como faculdade de concluir]" (p. 144).

A prova vem no parágrafo seguinte, no qual Kant passa dos imperativos hipotéticos para os categóricos apenas retirando o fim que dava àqueles sua razão de ser. A questão se insinua através do conceito de imperativo categórico e vai no sentido de uma identificação do entre "é bom fazer $x$ " e "é racional fazer $x$ ".

A ntes que Kant se volte então para a questão de saber em que pode consistir o imperativo categórico em termos de conteúdo, ele deve antes dizer o que se há de entender por um tal em geral. Isto agora é de fácil compreensão, depois de ter sido introduzida a fórmula "se queres $y$, faz $x$ " = "se queres $y$, é bom (ou melhor) fazer $x "$ ou (com base no exposto a pouco) "se queres $y$, é racional fazer $x$ ". Kant chama imperativos dessa forma de hipotéticos, porque fazer $x$ só é racional sob a hipótese que se queira y. Isto leva Kant, à p. 414, a conceber a possibilidade de um imperativo da razão sem um tal pressuposição. Este teria, por conse- 
guinte a forma "é bom fazer x" = "é racional fazer x", ponto sem condição. (p. 144)

Assim, no entender de Tugendhat, o imperativo categórico não é nada mais do que um imperativo hipotético sem condição, ou seja, que se tornou sua própria condição através de um conceito de razão como faculdade de fundamentação, dado pelo próprio Kant. Entretanto, a crítica de Tugendhat se aprofunda ao, novamente, introduzir uma pergunta na argumentação: até que ponto, pois, essa forma proposicional pode ter um sentido em geral?

Kant estabelece aqui, sem mesmo mencionar outras alternativas, que seu discurso sobre um "bem irrestrito", abordado na primeira proposição da la seção da Fundamentação, tem o sentido de "ordenado racionalmente", mesmo que a isto se possa objetar que este discurso sobre uma ação que é para ser racional em si mesma, e não só relativamente a algo, nem tem sentido. (p. 145)

Esse é, como afirma o próprio Tugendhat, o ponto decisivo de sua argumentação contra Kant.

A o introduzir a indicação kantiana de que épossível justificar tal passo argumentativo, isto é, fundamentar absolutamente o bem irrestrito da moral, Tugendhat expõe sua interpretação de Kant ao afirmar que para o próprio Kant a situação metodológica, e daí toda a aproximação do problema, é outra:

Ele acha que a proposição é inteligível e que a questão seria apenas referente à possibilidade de lhe dar um determinado conteúdo inteligível e daí, naturalmente também necessário. (p. 145)

Ao contrário, para Tugendhat, o passo dado por Kant ao fundamentar o imperativo categórico na razão permanece sem sentido. Isso porque Kant realiza esse passo às custas daquela razão como faculdade de concluir. U ma citação da Fundamentação é capital 
para a conclusão posterior de Tugendhat. Ela se encontra no $\S 28 \mathrm{e}$ é imediatamente anterior à primeira formulação do imperativo categórico.

Se me represento... um imperativo categórico, então sei de imediato o que ele contém. Pois como o imperativo só contém além da lei a necessidade da máxima de ser conforme a esta lei e a lei não traz em si nenhuma condição, à qual ela seria restrita, assim não resta senão a universalidade de uma lei em geral, com que deve concordar a máxima da ação... 0 imperativo categórico é, pois, um único e precisamente este: age somente de acordo com aquela máxima, pela qual podes, ao mesmo tempo querer que ela se torne uma lei universal. (p. 146)

Para Tugendhat, o erro de Kant está em imaginar o imperativo categórico como sendo um hipotético sem sua condição, ou seja, que se retirarmos a condição de um imperativo hipotético, acharemos a universalidade da própria razão, e é ela que irá fundamentar o próprio imperativo categórico e a ética kantiana.

A conclusão queKant tira na segunda proposição da citação anterior, de que, se a condição (portanto a proposição condicional) deixa de existir, somente resta a "universalidade de uma lei geral", é então claramente um non sequitur. (p. 146)

U m non sequitur significa que de uma premissa dada não se pode afirmar com certeza que se siga uma conseqüência, e, mesmo assim, Kant toma como verdadeiro esse raciocínio. Vale a pena lembrar al guns passos da argumentação de Tugendhat para colocar as idéias em ordem. Ele identifica duas noções diferentes de razão dentro do pensamento moral de Kant, depois ele vincula uma delas aos imperativos hipotéticos e a outra aos imperativos categóricos. D epois, ele afirma que Kant deriva os imperativos categóricos dos hipotéticos a partir de uma ausência de condição, que expo- 
ria a fundamentação destes em um princípio universal de uma lei geral.

Ao comentar o início da terceira seção da Fundamentação, Tugendhat amplia as críticas ao conceito de razão kantiano, afirmando que 0 recurso à natureza numênica do homem, um recurso antropológico, não é nada além de um salto mortal para um plano supra-sensível tão injustificado quanto o non sequitur do imperativo categórico.

\section{Kant}

A terceira seção da Fundamentação da metafísica dos costumes é consagrada ao conceito de liberdade e sua relação com a moralidade e com o imperativo categórico. N ela Kant busca esclarecer como são possíveis imperativos categóricos entendidos como juízos sintéticos a priori. Antes disso, porém, Kant quer afirmar a idéia positiva de liberdade como uma propriedade da vontade de todos os seres racionais. 0 que significa isso? $\mathrm{G}$ rosso modo, a tentativa de Kant caminha no sentido de tentar provar que é possível superar a falácia naturalista de Hume com uma referência a um mundo inteligível, do qual a razão faz parte enquanto constitutiva do ser humano.

Kant parte de uma espécie de circularidade - ou equivalência - dos conceitos de liberdade e autonomia da vontade, ou seja, a capacidade que a vontade tem de colocar para si leis que nada têm a ver com o mundo sensível.

Consideramo-nos como livres na ordem das causas eficientes, para nos pensarmos submetidos a leis morais na ordem dos fins, e depois pensamo-nos como submetidos a estas leis porque nos atribuímos a liberdade da vontade; pois liberdade e própria legislação da vontade são ambas autonomia, portanto conceitos transmutáveis, um dos quais, porém não pode, por isso mesmo, ser usado para 
explicar o outro e fornecer seu fundamento, mas quando muito apenas para reduzir a um conceito único, em sentido lógico, representações aparentemente diferentes do mesmo objeto. ${ }^{2}$

Kant demonstra estar bastante consciente de uma falha que, curiosamente, Tugendhat vai acusar aÉ tica do discurso, de H abermas, qual seja, a de utilizar o conceito usado na definição. Kant quer escapar desse problema apelando para a tal dimensão a priori, um mundo inteligível onde as leis da natureza não têm lugar. Essa diferença está incrustada na própria natureza humana - daí a dimensão antropológica do problema -, dentro da divisão entre fenômeno e coisa-em-si. Nós somos fenômenos ao mesmo tempo em que também somos coisa-em-si, cuja definição Kant dá negativamente como um substrato residual da eliminação de tudo o que é fenômeno, ou seja, tudo que pode ser compreendido pelo entendimento (Verstand). A dicotomia entre razão e entendimento corresponde a essa divisão central. D aí deriva o fato de que não se pode conhecer esse mundo, uma vez que o processo de conhecimento é levado a cabo pelo entendimento e esse só pode conhecer o que é fenômeno.

Por isso Kant afirma que não é possível, em última instância, responder a pergunta "donde provém que a lei moral nos obrigue?" A resposta a essa pergunta, do ponto de vista kantiano, é um claro limite da razão.

Como ser racional e, portanto, pertencente ao mundo inteligível, o homem não pode pensar nunca a causalidade de sua própria vontade senão sob a idéia da liberdade, pois que a independência das causas determinantes do mundo sensível...é liberdade. (p. 154)

Assim, a resposta de como são possíveis os imperativos categóricosé, grosso modo, a de que el es são possíveis porque o homem é de tal forma estruturado que possui uma faculdade, a razão, que participa de um mundo inteligível impossível de se conhecer. Daí 
também, reconhece Kant, a precariedade de uma explicação baseada nessa distinção.

Por isso a liberdade é apenas uma idéia da razão cuja realidade objetiva é em si duvidosa; a natureza, porém, é um conceito do entendimento qu demonstra, e tem necessariamente de demonstrar, a sua realidade por exemplos da experiência. (p. 156)

Esse caráter provisório da idéia de liberdade é fundamental para todo o problema da justificação das ações a partir do conceito forte de razão kantiano, como Tugendhat o quer definir. Para ele, essa referência a um mundo inteligível não faz sentido, e a idéia de um imperativo categórico é formalmente derivada dos imperativos hipotéticos por subtração, o que a tornaria imediatamente um non sequitur, ou seja, uma inferência inválida. D o fato de que eu possa subtrair de juízos condicionais a sua condição, não se segue que reste apenas uma lei universal a que a razão se impõe.

0 que podemos perguntar agora é o seguinte: por que Tugendhat gasta tanta tinta procurando provar uma falha na argumentação kantiana dentro da segunda seção e apenas toca de leve no problema mais agudo da terceira seção, ou seja, o limite dessa razão fundante a que ele atribui o imperativo categórico?

A discussão de Tugendhat com Kant nessa parte da terceira seção é permeada pela presença de $H$ ume, na aquiescência kantiana ao reino dos interesses. Nesse passo Tugendhat vê a vitória do argumento humeano: aquilo que nos move são nossos interesses, e uma razão pura nada poderia no mundo real das sensações. Kant concede esse ponto, mas afirma, ao mesmo tempo, quea moralidade pertence a uma outra dimensão do homem, uma dimensão, se se quiser, transcendental.

O ra, a liberdade é uma mera idéia cuja realidade objetiva não pode ser de modo algum exposta segundo leis naturais e, portanto, em nenhuma experiência também, que, por 
conseqüência, uma vez que nunca se the pode supor um exemplo por nenhuma analogia, nunca pode ser concebida nem sequer conhecida. Ela vale somente como pressuposto necessário da razão num ser que julga ter consciência de uma vontade, isto é, duma faculdade bem diferente da simples faculdade de desejar. (p. 159)

A liberdade e, por conseqüência, também a moralidade só podem ser pensadas e nunca conhecidas. Daí que o conceito de razão forte e fundante a que Kant se refere tem, ele mesmo, um fundamento mais profundo que éa própria constituição da natureza humana. Afinal, somos seres capazes de pensar e, por conta disso, capazes de nos impor uma idéia de liberdade que jamais iremos conhecer, mas que, entretanto, temos todo o direito de pensar.

\section{Condusão}

Dizer que toda ética já é um segundo momento dentro de uma ontologia parece reforçar a falácia naturalista de que daquilo que é não se pode derivar o que deve ser. A pergunta antropológica kantiana - o que é o homem? - que reúne a resposta a todas as outras questões relevantes para o filósofo de Königsberg é, na verdade, uma referência direta à ontologia. Assim, na terceira seção da Fundamentação, Kant só pode ver uma saída ontológica para o problema teórico de uma razão que não pode ser conhecida mas tem de servir como pressuposto à qualquer ação humana que se pretenda moral.

A solução kantiana jamais poderia agradar a Tugendhat, cujo ponto de partida é sempre o problema da fundamentação. Mas, para ele, ainda é possível fundamentar ações morais, no sentido de queainda é possível encontrar razões para se preferir essa ou aquela ação em virtude de sua moralidade. 0 problema, para Tugendhat, é que o mero fato de que usamos as palavras "bom" e "mau" em um sentido absoluto não resulta da existência efetiva desse sentido. 
A alternativa seria abandonar o problema da fundamentação como algo que possa ser alcançado. Não seria possível, em última instância e para além dos nossos interesses mais concretos, justificar a moralidade de uma ação - entendendo aqui justificação como dar razões absolutas para se querer realizar tal ação. A solução desse problema não seria filosófica mas sociológica. Fora isso, nos sobra apenas o sem-sentido do puro existir, ou seja, sobra a angústia de não se poder mais fundamentar nossos atos.

A credito, pelo contrário, que uma fundamentação das ações morais, se ainda é possível falar em tal coisa, não se encontra em nossa capacidade de dar razões, isto é, em nossa capacidade argumentativa, mas na constituição mesma do nosso existir, como queria Kant na terceira seção. U ma saída é dizer que o próprio homem é condição de possibilidade para uma (ou qualquer) ética, 0 que vale dizer: o ser do homem é o fundamento último das ações humanas. Essa tese deriva de uma interpretação particularmente kantiana que Ernildo Stein faz de H eidegger. Para Stein, o projeto de Ser e tempo se articula em torno da resposta à pergunta antropológica de Kant, sendo que $0 \mathrm{D}$ asein seria a resposta.

0 problema é que 0 Dasein heideggeriano não comporta nenhum conteúdo, qualquer que seja, em sua definição. Eleéapenas sua possibilidade. 0 que isso significa? Significa que o ser do homem não é nada de específico, mas apenas o nó de possibilidades que ele representa. Assim, a moralidade é apenas um dos modos de ser do homem e sua existência se deve ao simples fato de que, desde 0 início, era bastante possível que existisse. Assim, longe de possuir uma essência determinada que Ihe indicasse como devem ser suas ações, a característica fundamental desse ente que é o homem seria apenas o fato de que sua essência é sua existência. Dito de outra forma, o que é o homem? Ele é sempre aquilo que pode se tornar, nada mais, nada menos. Esse conceito não carrega nenhuma normatividade, ou seja, não dita conteúdos. Ele apenas apresenta a dimensão ética da existência como uma possibilidade de ser do homem. Isso elimina a falácia naturalista porque adota um ponto 
de partida não normativo para a ética, embora baseie sua existência naquilo que é, o ser do homem, não prescreve o que deve ser, pois como desdobramento legítimo de uma possibilidade do ser do homem a ética é sempre o que deveria ser, manifestação do ser do Dasein.

Ainda assim, uma questão permaneceria nos atormentando. Baseada na ontologia, a ética não distinguiria entre ações boas ou más, não justificaria porque devemos agir de uma maneira e não de outra. O ra, isso seria se ater à estrutura da justificação (ou fundamentação), al go que não poderia ser alcançado. 0 que se deve é refletir sobre a seguinte questão: se não podemos mais fundamentar ações morais, então o que nos resta, como filósofos, dizer sobre 0 assunto? R esta-nos apontar para o fato de que a moralidade pode não ser mais bem discutida no campo da argumentação, da fundamentação, mas sim no da ontologia. Isto é, o bem e o mal são possibilidades do homem decididas a partir de si mesmo como ente capaz de se colocar a questão do sentido do Ser. Sentido não significa fundamentação, ou melhor, fundamentação não significa prova. D escobrir o sentido do Ser significa esclarecer as possibilidades do homem como ser moral e não fundamentar esse ou aquele comportamento; isso já seria uma tarefa secundária, legada às atividades ônticas do homem (está pressuposta aqui a diferença ontológica heideggeriana). Da ontologia, enfim, não derivam normas, mas a simples possibilidade de qualquer norma. Essa perspectiva radical sobre os fenômenosfoi um dos pontos fundamentais do porquê de $\mathrm{H}$ eidegger ter insistido tanto na ontologia em Ser e tempo, chegando mesmo a equipará-la à fenomenologia.

0 fracasso das estruturas de fundamentação das ações morais sem recorrer a um plano metafísico fantasioso, ou como gostaria Tugendhat, sem recorrer a cambal hotasfilosóficas, pode nosmostrar que estávamos tratando do problema de um ponto de vista equivocado, ou seja, não essencial. Se pensarmos na constituição do homem, como fez Kant, como ontologicamente pertencente ao Ser, podemos dar aos nossos olhos um frescor novo, no sentido 
fenomenológico de "voltar às coisas mesmas", e observar o problema ético de uma nova perspectiva. Isso causaria o desconforto adicional de transformar qualquer trabalho de desconstrução do problema da fundamentação em um esforço positivo de destruição ou desencobrimento do que permanecia velado, do caráter invariavelmente ontológico das perguntas radicais em filosofia.

ABSTRACT: The notion of ethic defended by the analytic tradition is based on the premise that every ethic has to be normative and therefore must justify the adoption of principles of moral by means of a rational argumentation. In his book, "Lessons on Ethic", E. Tugendhat tries to establish a dialog with the philosophical tradition, specially with Kant, in order to identify and to evaluate the most important systems of ethic. Tugendhat's argumentation pends to a contemporary contractualism, although he keeps trying to maintain kantian's aspects of the foundation of the categorical imperative. In this paper I will argue that the Tugendhat's interpretation of the kantian's system is only partially correct. By ignoring the notion of freedom Tugendhat become vulnerable to the ethical scepticism, because he can't go deeper into the discussion on the ontological level as Kant did.

Key words: Kant, ontology, moral judgements, moral justification, Tugendhat.

\section{Notes}

1 Tugendhat, Ernest. Lições sobre ética. Petrópolis: Vozes, 1997. p. 142. As demais citações dessa seção, retiradas desta obra, virão acompanhadas apenas pelo número da página.

2 Kant, Imannuel. Fundamentação da M etafísica dos C ostumes. São Paulo: A bril Cultural, 1980. p. 152. As demais citações virão acompanhadas pelo número da página. 